\title{
Building a cloud in the southeast Atlantic: understanding low-cloud controls based on satellite observations with machine learning
}

\author{
Julia Fuchs $^{1,2}$, Jan Cermak ${ }^{1,2}$, and Hendrik Andersen ${ }^{1,2}$ \\ ${ }^{1}$ Institute of Meteorology and Climate Research, Karlsruhe Institute of Technology (KIT), Karlsruhe, Germany \\ ${ }^{2}$ Institute of Photogrammetry and Remote Sensing, Karlsruhe Institute of Technology (KIT), Karlsruhe, Germany \\ Correspondence: Julia Fuchs (julia.fuchs@kit.edu)
}

Received: 14 June 2018 - Discussion started: 9 July 2018

Revised: 12 October 2018 - Accepted: 4 November 2018 - Published: 22 November 2018

\begin{abstract}
Understanding the processes that determine lowcloud properties and aerosol-cloud interactions (ACIs) is crucial for the estimation of their radiative effects. However, the covariation of meteorology and aerosols complicates the determination of cloud-relevant influences and the quantification of the aerosol-cloud relation.

This study identifies and analyzes sensitivities of cloud fraction and cloud droplet effective radius to their meteorological and aerosol environment in the atmospherically stable southeast Atlantic during the biomass-burning season based on an 8-day-averaged data set. The effect of geophysical parameters on clouds is investigated based on a machine learning technique, gradient boosting regression trees (GBRTs), using a combination of satellite and reanalysis data as well as trajectory modeling of air-mass origins. A comprehensive, multivariate analysis of important drivers of cloud occurrence and properties is performed and evaluated.

The statistical model reveals marked subregional differences of relevant drivers and processes determining low clouds in the southeast Atlantic. Cloud fraction is sensitive to changes of lower tropospheric stability in the oceanic, southwestern subregion, while in the northeastern subregion it is governed mostly by surface winds. In the pristine, oceanic subregion large-scale dynamics and aerosols seem to be more important for changes of cloud droplet effective radius than in the polluted, near-shore subregion, where free tropospheric temperature is more relevant. This study suggests the necessity to consider distinct ACI regimes in cloud studies in the southeast Atlantic.
\end{abstract}

\section{Introduction}

Low-level clouds play a major role in the climate system via their impact on the Earth's energy budget and water cycle (Boucher et al., 2013). However, the estimation of their potentially large negative radiative effect is prone to large uncertainties as processes that govern cloud microand macro-physical properties, i.e., aerosol-cloud interactions (ACIs) and the impact of changing environmental conditions on low clouds are not sufficiently understood (Bony and Dufresne, 2005; Medeiros et al., 2008). Maritime stratocumulus clouds, persisting over the relatively clean southern oceans are thought to be especially sensitive to aerosols, exerting a strong cloud albedo effect of $-0.2 \mathrm{~W} \mathrm{~m}^{-2}$ (Platnick and Twomey, 1994; Quaas et al., 2008). One of these regions, the southeast Atlantic (SEA), has become a very popular region for studies of low-cloud processes and ACI in the last decade (e.g., Chand et al., 2009; Muhlbauer et al., 2014; Painemal et al., 2014; Andersen and Cermak, 2015; Adebiyi et al., 2015; Fuchs et al., 2017).

The semipermanent low-cloud cover of the SEA is driven by the cold Benguela current offshore the NamibianAngolan coast and maintained by large-scale subsidence (Wood, 2012). During the biomass-burning season in JulyAugust-September (JAS), carbonaceous aerosols are advected over the oceanic boundary layer and frequently build a thick layer above the clouds. Black carbon aerosol particles can act as cloud condensation nuclei as they are entrained at cloud-top (Seinfeld et al., 2016) or can indirectly alter cloud cover through the strengthening of the inversion by absorption of shortwave radiation above the cloud (Wilcox, 2010; Bond et al., 2013; Li et al., 2013). 
Despite advances on the basis of large eddy simulations (e.g., Yamaguchi and Randall, 2008; Jones et al., 2014), Lagrangian approaches (e.g., Mauger and Norris, 2010) and observational studies (e.g., Zuidema et al., 2016), the complex mechanisms between low clouds, boundary layer processes, thermodynamics and large-scale circulation are not sufficiently understood. Untangling the drivers of cloud properties is challenging, as meteorological parameters and aerosols covary (Mauger and Norris, 2007; Fan et al., 2016), vary spatially and have different timescales (Jones et al., 2014; Eastman et al., 2016; de Szoeke et al., 2016).

In a recent study, Fuchs et al. (2017) showed that air-mass origins can explain some of the variability of cloud microphysics in the SEA, with clear spatial differences in the involved processes. Analyses of cloud sensitivities in the SEA would therefore benefit from a subregional determination of large-scale, thermodynamic and aerosol drivers of cloud property changes. Relevant mechanisms for changes of lowcloud properties are studied here, focusing on two questions:

- What are the subregional differences in cloud sensitivities to various geophysical parameters?

- How do these determinants influence cloud properties and their response to atmospheric aerosol loading?

In this study a machine learning approach is used to predict cloud fraction and cloud droplet effective radius in the SEA based on satellite and reanalysis data. This study does not aim to simulate microphysical cloud processes and individual feedback mechanisms at the level of detail of a cloudresolving model, but instead intends to represent nonlinear patterns of cloud adjustments to the large-scale and thermodynamic environment in a coherent, multivariate statistical model.

\section{Methods}

\subsection{Data}

Cloud fraction $(\mathrm{CF})$, cloud droplet effective radius (REF) and aerosol optical depth (AOD) are obtained from the 8day level 3 (L3) product of the MODerate-resolution Imaging Spectroradiometer (MODIS) instrument aboard the Aqua platform (collection 6). The data cover a temporal range from 2002 to 2012 during the biomass-burning season in JulyAugust-September. The REF product is based on singlelayer liquid clouds to avoid the effects of overlapping cirrus clouds (Hubanks et al., 2018).

The following thermodynamic and dynamic parameters of the ERA-Interim reanalysis data set of the European Centre for Medium-Range Weather Forecasts (ECMWF; Dee et al., 2011) are used: lower tropospheric stability (LTS); relative humidity at 950, 850 and $700 \mathrm{hPa}$ (RH950, RH850, RH700); surface wind speed at $10 \mathrm{~m}$ (WSP10); sea surface temperature (SST); and temperature at $700 \mathrm{hPa}(\mathrm{T} 700)$, zonal wind speeds at $600 \mathrm{hPa}$ (U600) and mean sea level pressure (MSLP).

The 6-hourly ERA-Interim reanalysis data is also used in the calculation of 5-day backward air-mass trajectories with the HYSPLIT model using geopotential height, relative humidity, temperature, $u / v$ wind components and vertical velocity at different subsets of 25 pressure levels. The backward trajectories are initialized at 12:00 UTC, at each grid point of the study area and at a subregional mean cloud-top altitude obtained from the CALIPSO Level-2 $5 \mathrm{~km}$ layer cloud product (version 3, daytime) (Winker et al., 2009).

All meteorological variables are interpolated to $0.5^{\circ}$ for the trajectory analysis and subsequently averaged to the MODIS L3 8-day product of $1^{\circ}$. The temporal resolution of 8 days allows large-scale, thermodynamic (see McCoy et al., 2017) and aerosol forcings of cloud properties to be combined simultaneously on a synoptical scale. However, it must be taken into account that clouds adjust on different timescales (hours to several days) to their environment (Klein, 1997; Mauger and Norris, 2010; Jones et al., 2014; Adebiyi and Zuidema, 2018) and thus processes relevant on shorter timescales might be underrepresented in the data set.

\subsection{Subregional GBRT models}

In this study $\mathrm{CF}$ and REF are simulated based on a selected predictor set (AOD and meteorological parameters) in the SEA $\left(10-20^{\circ} \mathrm{S}, 0-10^{\circ} \mathrm{E}\right.$, as analyzed in Klein and Hartmann, 1993) using Gradient Boosting Regression Trees (GBRTs). To account for subregional spatial variability of e.g., cloud altitude, aerosol occurrence, boundary layer dynamics and large-scale dynamics, the study area is divided into four equal-sized subregions of $5^{\circ}$ by $5^{\circ}$ : the northwestern (NW), northeastern (NE), southwestern (SW), southeastern (SE) subregion. Consequently, drivers of CF and REF are analyzed in the environmental context of each subregion individually, yielding eight (four subregions $\times$ two predictands) subregional statistical models each based on approximately 2000 data points per parameter.

GBRTs are a highly robust machine learning technique aimed at mapping the relationship between a set of predictors and a predictand. The GBRT algorithm produces an ensemble of many weak prediction models ("base learners" or trees), which are expanded in stages, following the gradient descent of a specified loss function (Friedman, 2001; Natekin and Knoll, 2013). In each stage, a new decision tree is fitted to the residuals of the previous tree, and the prediction function is updated. The sum over all decision trees results in a robust statistical model that can map nonlinear dependencies between predictors and the predictand. These statistical models are widely used in environmental and atmospheric sciences (e.g., Sayegh et al., 2016; Carslaw and Taylor, 2009) due to their predictive power, simple implementation and flexibility toward qualitative and quantitative data (Hastie et al., 2009). However, GBRTs require careful 
Table 1. Model parameter grid tested during 3-fold cross-validation.

\begin{tabular}{llr}
\hline Model parameter & Impact on model performance & Parameter grid tested \\
\hline Learning rate & Low values allow for better generalization & {$[0.05,0.04,0.03,0.02,0.01,0.009,0.007,0.003]$} \\
Boosting iterations & Large values improve performance, but risk overfitting & {$[2000,2400,2800,3200,3600,4000]$} \\
Maximum depth of a tree & Small numbers prevent overfitting & {$[2,3,4]$} \\
Minimum samples per leaf & Small values risk overfitting & {$[10,14,18]$} \\
\hline
\end{tabular}

parameter tuning (e.g., boosting iterations, learning rate), as the goal is to represent the given data and relationships as accurately as possible, without overfitting the model. The GBRT implementation of the scikit-learn library was used and adapted to this end (Pedregosa et al., 2011).

To train, test and validate the statistical models, the data set is split into three random parts, the training (50\%), test $(20 \%)$ and validation $(30 \%)$ data sets. The model setup is tuned based on the training data by testing various scenarios specified by a parameter grid through 3 -fold cross-validated search. During cross-validation, the training set is divided into three parts: two-thirds are used for training and one-third for testing. Each parameter combination from the grids, listed in Table 1 , is evaluated based on the $r^{2}$ score obtained in correlating predicted and observed output. The obtained hyperparameter with the highest performance is chosen to set up the model. In general, a high number of boosting iterations and a low learning rate will increase the model's ability to make predictions on an unseen data set (generalize), its performance and computational demand during training.

The Huber loss function is chosen due to its higher robustness compared to other continuous loss functions, e.g., least squares (Huber, 1964; Natekin and Knoll, 2013). A subsample rate (a random fraction of the training data used for fitting) of 0.8 is selected to reduce variance and increase model robustness. All remaining parameter settings are left at their default values as provided by the gradient boosting regressor function (Pedregosa et al., 2011).

Providing the optimal model setup, the model is fitted to the training data. In parallel, the test data set is used to regularize the GBRTs by determining the final boosting iteration. The learning stops when the mean squared error (MSE) of the test data set is increasing or constant five times in a row. The cross-validated tuning of the hyperparameter, the choice of a robust loss function and the implementation of an early stopping rule ensure the computing of robust GBRT models, which do not overfit to the training data.

To evaluate the overall performance of the GBRTs, two measures, the coefficient of determination $\left(r^{2}\right)$ and the root mean squared error (RMSE) between predicted and REF, are calculated using the independent validation data set. To ensure comparability between the RMSE of the CF and REF performance the RMSE is normalized (NRMSE) by the difference between the maximum and minimum observed values.
The final model can be interpreted using "partial dependence", which expresses the averaged change of a cloud property relative to a selected predictor set by averaging over all complement predictors (Friedman, 2001). This is done by computing an average prediction function for a given range of values (1st-99th percentile) estimated from the target predictor. Each grid point of the target predictor is fixed while the values of the complement predictors vary over their marginal probability density. As a result, the partial dependence represents the influence of one target variable, accounting for the full meteorological variation of the complement predictors. Accordingly, it is assumed that covarying cloud properties that are not explicitly considered in this study (e.g., liquid-water path) are indirectly constrained to some extent by the statistical model. This means that in the model the variation of meteorological parameters would implicitly represent different cloud states. The absolute difference of the maximum and minimum partial dependence is further used to compare the cloud property response due to the different predictors, and thus to obtain a general measure for the most important drivers in the different subregions. In order to analyze the joined influence of two variables on the predictand, two-variable partial dependence plots are used. For regression trees the implementation of partial dependence is straightforward and can be derived from the tree structure itself through a weighted tree traversal proposed by Friedman (2001). The partial dependence obtained from the GBRT model is added by the cloud property mean value for reference. Marked steps in the partial dependencies have to be interpreted with caution (e.g., Fig. 5), as they can be in part caused by the decision-tree-based algorithm, dividing the parameter space into separate regions.

In general, GBRTs are a powerful tool for representing nonlinear dependencies and emphasize subregionally important determinants for low clouds in the SEA. However, for the interpretation it must be considered that partial dependencies rely on a statistical model. That means that associations between predictors and predictand are not necessarily causal, as in every statistical model. The obtained relationships are assumed to mainly reflect processes at a subspatial scale during the biomass-burning season, but may be to a small extent attributed to spatial and intraseasonal variations. 
Table 2. Predictors and abbreviations used in the GBRT models.

\begin{tabular}{lll}
\hline Thermodynamic properties & Dynamic properties & Aerosol property \\
\hline Lower tropospheric stability (LTS) & Source latitude of air mass (Lat_src) & Aerosol optical depth (AOD) \\
Sea surface temperature (SST) & Source longitude of air mass (Lon_src) & \\
Temperature at 700 $\mathrm{hPa}$ (T700) & Wind speed at 10 m (WSP) & \\
Relative humidity at 700 hPa (RH700), & Zonal wind speeds at 600 hPa (U600) & \\
at $850 \mathrm{hPa}(\mathrm{RH} 850)$, at $950 \mathrm{hPa}(\mathrm{RH} 950)$ & Mean sea level pressure (MSLP) & \\
\hline
\end{tabular}

\subsection{Predictor selection}

The predictor selection pursues the goal of creating a simple model capable of capturing general thermodynamic, dynamic, stratification and aerosol patterns relevant for changes of cloud properties and is based on findings of previous studies (e.g., Norris and Iacobellis, 2005; Lacagnina and Selten, 2013; McCoy et al., 2017; Andersen et al., 2017; Fuchs et al., 2017; Adebiyi and Zuidema, 2018). A total of 12 predictors (see Table 2 for an overview) are chosen as inputs to the GBRTs due to their known forcing on CF and REF in the SEA. The listed parameters describe cloud-relevant environmental conditions at the sea surface (e.g., SST, MSLP), cloud level (RH950, RH850) and the free troposphere (e.g., T700, RH700).

The lower tropospheric stability, a proxy for inversion strength and sea surface temperature are primary controls for the multiday and seasonal cloud occurrence in the SEA (Klein and Hartmann, 1993; Klein et al., 1995; de Szoeke et al., 2016). Here, LTS is defined as the difference between potential temperature $(\theta)$ at 850 and $1000 \mathrm{hPa}$ as described in Painemal and Zuidema (2010).

As free tropospheric and cloud-level humidity influence dry-air entrainment and cloud characteristics in marine low clouds (Wood, 2012; Jones et al., 2014; Bretherton et al., 2013; Andersen et al., 2017), relative humidity values at 700, 850 and $950 \mathrm{hPa}$ are selected as predictors.

The large-scale circulation and the history of air masses drive boundary layer cloudiness (Klein et al., 1995; Mauger and Norris, 2007; Fuchs et al., 2017). In order to represent the influence of external dynamics on the local cloud field, the latitude and longitude of the origin of 5-day backward trajectories (Lat_src, Lon_src) are included as predictors in the statistical models. The backward trajectories are initiated at the mean cloud-top altitude in every subregion: 1090 (NW), 1060 (NE), 1180 (SW) and $810 \mathrm{~m}$ (SE). Air-mass dynamics, including the surface wind speed and the strength of subtropical anticyclones, are important drivers for cloud amount, physical and radiative properties (Klein et al., 1995; Brueck et al., 2015; Kazil et al., 2016; Bretherton et al., 2013) and considered as predictors in the GBRT models. The strength of the South African Easterly Jet is observed to influence the marine boundary layer during the month of September to October through changes in stability and subsidence. It is defined as easterly wind speeds exceeding $6 \mathrm{~m} \mathrm{~s}^{-1}$ between
5 and $15^{\circ} \mathrm{S}$ at $650-600 \mathrm{hPa}$ (Adebiyi and Zuidema, 2016). In this study its influence is assumed to extend over the study area and thus the zonal wind field at $600 \mathrm{hPa}$ is used.

Aerosols interact with liquid clouds in a multifaceted way (Fan et al., 2016). According to Twomey's theory of the first aerosol indirect effect, aerosols act as cloud condensation nuclei and influence cloud microphysics and albedo (Twomey, 1974). The Albrecht hypothesis states that this effect may result in a prolonged cloud lifetime and increased cloud optical thickness, liquid water path and cloud fraction through the suppression of precipitation (Albrecht, 1989). For the investigation of cloud susceptibility to aerosols, the AOD is considered as a proxy for cloud condensation nuclei. While the aerosol index may be a better proxy for cloud condensation nuclei than AOD (Stier, 2016), its computation requires the Angström exponent, which is not available in the 8-day MODIS L3 product (Levy et al., 2013). Studies that observed the bivariate relations between AOD and cloud properties are numerous (e.g., Kaufman, 2005, 2006; Grandey et al., 2013), but spurious correlations exist. The strength of the relation between AOD and CF or REF is depending on satellite artifacts in the vicinity of clouds, e.g., cloud contamination and three-dimensional radiative effects (Várnai et al., 2013; Christensen et al., 2017) as well as on meteorological conditions, e.g., aerosol hygroscopic swelling with humidity (Kaufman et al., 2005; Quaas et al., 2010). In turn aerosols may alter the cloud's thermodynamic environment, through the semidirect effect, where absorbing aerosol layers increase stability through local heating (Johnson et al., 2004; Li et al., 2013).

The application of the GBRTs aims at finding subregional patterns of relevant low-cloud drivers, without creating a model which fully covers the interactions between clouds and their environmental conditions. The predictor set was selected in a way to reduce covariation. Thus, the choice of predictors reflects the compromise between characterizing the atmospheric state sufficiently without creating a model that lacks interpretability. 


\section{Results and discussion}

\subsection{Validating GBRT models}

In this section the statistical models are evaluated, important features within the models are identified and, subsequently, partial dependencies (see Sect. 2.2 for more information) of the most important determinants are presented.

Figure 1 shows the validation results for the GBRTs predicting CF and REF in the different subregions. The performance is compared to a multiple linear regression analysis, using the same data basis. The correlation $\left(r^{2}\right)$ of predicted and observed values in the GBRT model ranges from 0.57 to 0.79 in the different subregional models and is clearly superior to the $r^{2}$ of the multiple linear regression model ranging from 0.32 to 0.58 in the different subregions. The $r^{2}$ range (error bars) of 10 random GBRT simulations based on 10 different data random splits typically does not exceed the $r^{2}$ range of the linear regression using the 10 different data random splits, indicating constant model performances. Both models show a low NRMSE, that is on average $\sim 5 \%$ for the GBRTs and $\sim 7 \%$ for the linear regression.

Considering the GBRT models only, two aspects can be noted. First, in the northern subregions the REF models perform slightly better than the CF models, and second, the CF model shows subregional variations. Differences of model skills might be attributed to a higher variability of the cloud properties and meteorological conditions prevailing in the SW compared to the NE (Fuchs et al., 2017; Adebiyi and Zuidema, 2018; Rahn and Garreaud, 2010), or point to missing information in the predictor set of the NE CF model.

As all GBRT models have been shown to adequately represent parameter relations, the statistical relationships within the models are subsequently analyzed with the purpose of inferring process relationships.

\subsection{Sensitivity of cloud fraction and droplet radius}

Figure 2 shows the multi-model mean absolute difference of the maximum and minimum partial dependence of CF (a) and REF (b) on the predictors as a measure for the sensitivity of these cloud properties to the various predictors.

In general, LTS, surface wind speed and relative humidity at $950 \mathrm{hPa}$ play an important role for the determination of CF; however, marked subregional differences in their sensitivities can be identified (Fig. 2a). It is notable that CF is most sensitive to LTS in the southern subregions. In the northeast, the impact of relative humidity at $950 \mathrm{hPa}$ on CF is markedly reduced. Here, surface wind speed seems to be a key driver of CF. Changes in AOD seem to have a marked impact on CF only in the eastern subregions that are frequently exposed to high aerosol loadings.

The REF (Fig. 2b) is largely controlled by the free tropospheric temperature in the NE subregion. Here, REF is, similar to CF, strongly influenced by surface winds. In the SE,

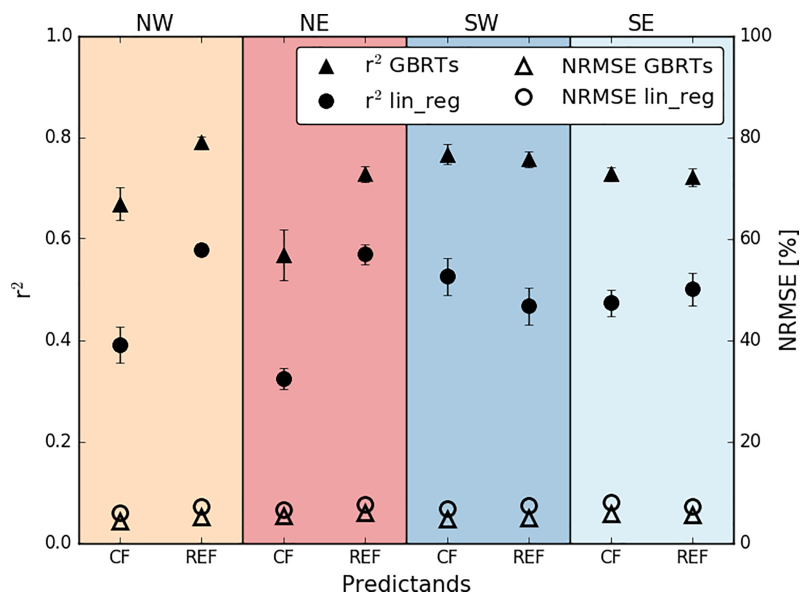

Figure 1. The overall mean quality of the GBRT models (triangles) is compared to a simple least squares linear regression (circles) for $\mathrm{CF}$ and REF in the four subregions NW, NE, SW and SE during JAS. The models are evaluated based on the coefficient of determination $\left(r^{2}\right)$ and normalized root mean squared error (NRMSE) between predicted and observed $\mathrm{CF}$ (REF). The error bars range from the minimum to maximum $r^{2}$ obtained from 10 different models using randomly chosen training data.

relative humidity at $950 \mathrm{hPa}$ is an important driver for REF, while in the other subregions, relative humidity at $850 \mathrm{hPa}$ has a stronger impact on REF due to the higher cloud level. In the SE, which is regularly exposed to the continuous warm and dry air advection from the coastal and continental region, an occasional moistening through dynamical changes may have a strong effect on cloud droplets of a thin cloud layer (Adebiyi et al., 2015).

The influence of dynamical parameters such as zonal wind at $600 \mathrm{hPa}$ and air-mass origin (Lon_src) on REF is especially relevant in the SW, while LTS is a prominent influence in the NW. As expected, the contribution of aerosols to changes in CF and REF is small compared to the main meteorological drivers. However, the absolute differences indicate that aerosols appear to be most important for REF in the relatively pristine $\mathrm{SW}$.

Based on these outcomes important predictors are brought into focus and the GBRT partial dependencies of CF and REF on selected predictor variables are analyzed in more detail in the following subsections.

\subsubsection{Thermodynamics}

In accordance with findings of earlier studies (Klein and Hartmann, 1993; Zhang et al., 2009), Fig. 3a shows that CF increases with LTS in all subregions. This relation is explained by reduced dry-air entrainment under stable conditions building a shallow, well-mixed and humid cloud layer (cf. Wood and Bretherton, 2006; Wood, 2012; Myers and Norris, 2013). Under very stable conditions, above $30 \mathrm{~K}$ temperature difference, the sensitivity of CF to LTS seems to 


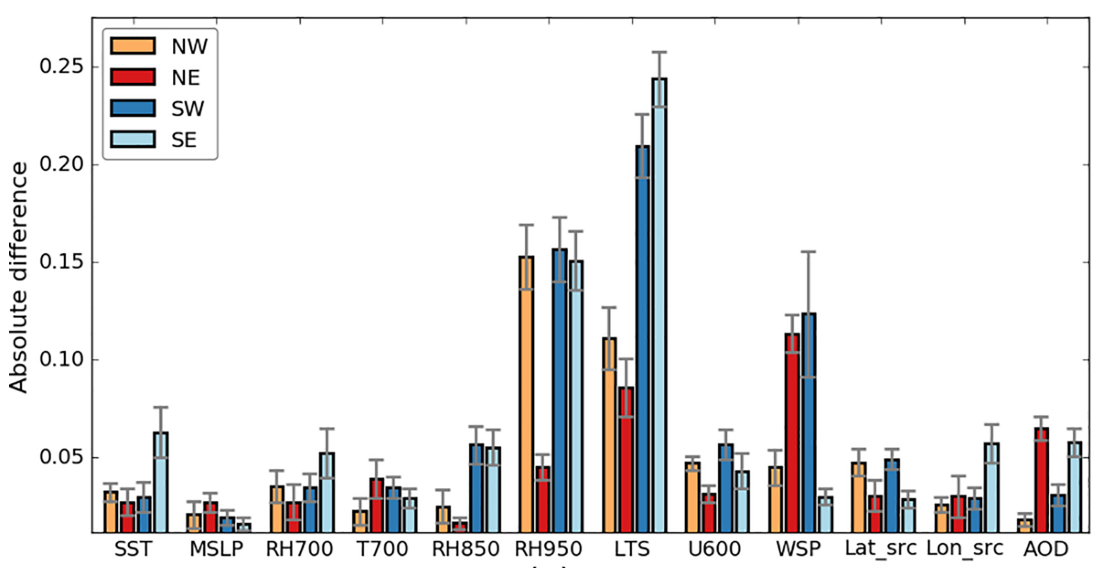

(a)

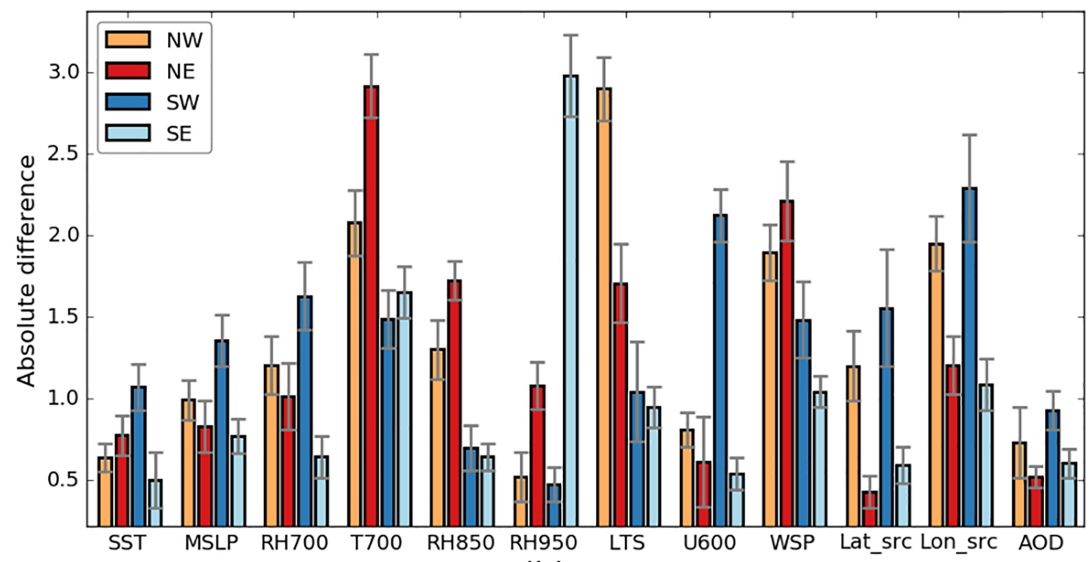

(b)

Figure 2. Mean absolute difference of maximum and minimum partial dependence of CF (a) and REF (b) on the predictors in the four subregions (colors) during JAS. "Error" bars show the minimum and maximum absolute difference of partial dependencies of all model runs.

be saturated and further stabilization does not increase the cloudiness anymore. This relates well to findings by Zhang et al. (2009), who detected the strongest CF sensitivity at intermediate LTS. It is remarkable that CF sensitivity to LTS in southern subregions is about twice as strong as in the northern subregions. This observation might be attributed to cloud breakup linked to midlatitude cyclones (Toniazzo et al., 2011; Fuchs et al., 2017). In contrast, in the NE the impact of LTS on CF is relatively weak as this area is characterized by more stable conditions with less thermodynamic variability.

The relation of REF and LTS (Fig. 3b) is the strongest in the NW. A marked jump at $\sim 30 \mathrm{~K}$ may indicate the transition from a stable, relatively well-mixed coupled stratocumulus regime with larger droplets to an unstable, decoupled regime, where cloud liquid water evaporation due to dry and warm air entrainment can reduce droplet size (Bretherton and Wyant, 1997).

While the partial dependence of T700 on CF shows no distinct pattern in any subregion, a strong REF sensitivity to T700 can be noticed, in particular in the NE. As droplet size is retrieved at the cloud top, it might be more sensitive to a free tropospheric warming at $700 \mathrm{hPa}$ and reduced dryair entrainment above. The cloud cover, through the cloud's vertical extent, is probably more sensitive to the $850 \mathrm{hPa}$ temperature, which is part of the LTS calculation (see Sect. 2.3).

\subsubsection{Dynamics}

Large-scale dynamics, here the origins of air masses, can influence cloud cover in the SEA in different ways (cf. Fuchs et al., 2017). Figure 4a shows the response of CF to changes in the latitudinal origin of air masses (Lat_src). While in the eastern subregions, CF seems largely insensitive to changes in Lat_src, CF in the western subregions is negatively associated with Lat_src: i.e., CF decreases the further north the air-mass origin. This likely points to findings of Fuchs et al. (2017), who found that long-distance air masses, induced by westerly disturbances, are related to increased boundary layer height, cloud fraction, cloud droplet sizes and liquidwater path in the western parts of the SEA. Air masses originating from $\sim 20(\mathrm{SW})$ and $\sim 15^{\circ} \mathrm{S}(\mathrm{NW})$ may contribute to the reduction in CF by subsiding dry air (Myers and Nor- 


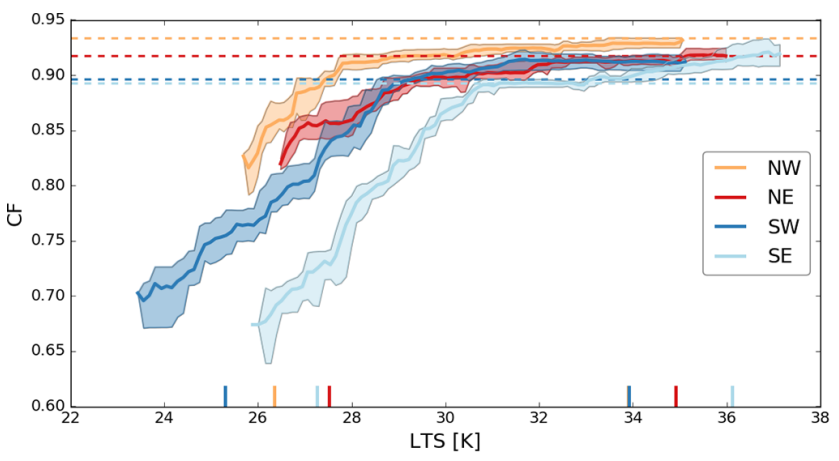

(a)

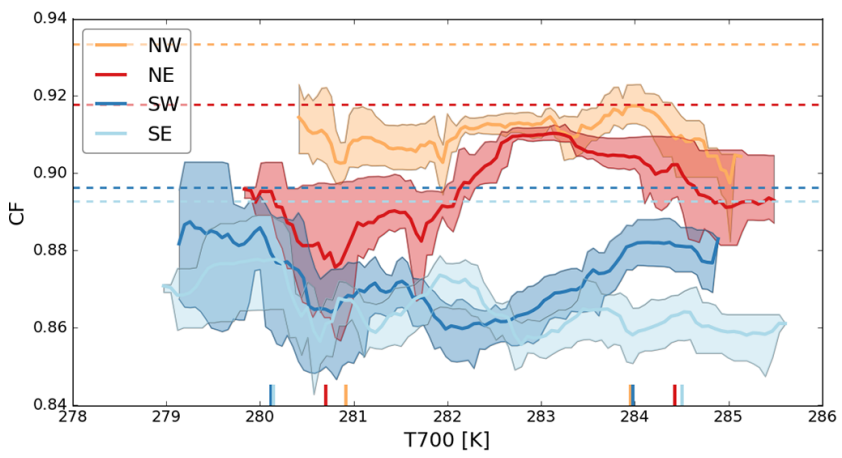

(c)

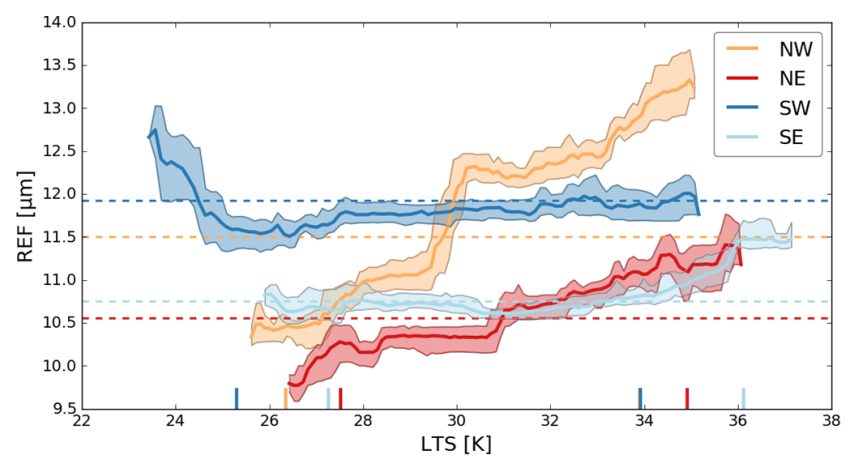

(b)

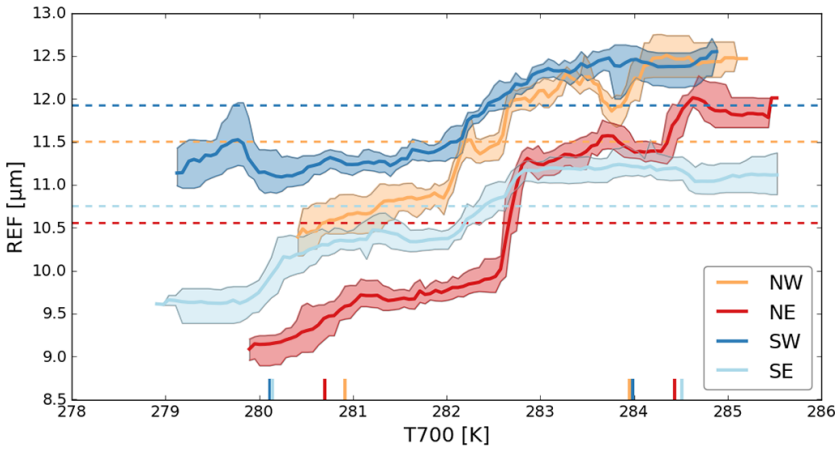

(d)

Figure 3. Mean partial dependence of CF and REF on LTS (a, b) and T700 (c, d) in the four subregions (colors) during JAS. Shaded areas mark minimum and maximum partial dependence obtained from all model runs. Horizontal dashed lines show the predicted mean. Vertical tick marks on the $x$ axis indicate 5th and 95th percentile of the observations.

ris, 2013). The shift of the CF minima between southern and northern subregions may be interpreted as time lag of these air-mass paths, reaching the southern subregions earlier. In parallel to $\mathrm{CF}$, the REF sensitivity to the latitudinal air-mass origin is particularly strong in the western subregions of the study area, especially the SW (Fig. 4b). The subregional difference between western and eastern subregions is even stronger than for CF. The NE shows only a weak response of REF to the latitudinal component of the air-mass origin due to the influence of mainly continental air-mass origins (Fuchs et al., 2017) ranging much more on the longitudinal scale (Fig. 3b).

The CF sensitivity to the surface wind field is shown in Fig. 4c. A clear increase in CF with higher surface wind speeds can be observed in the SW, where a change of wind speed of $1 \mathrm{~m} \mathrm{~s}^{-1}$ entails an increase in CF of more than $10 \%$. Strong surface winds may be associated with increased cold air advection and surface heat fluxes, favoring higher lowcloud amounts (Klein, 1997; Brueck et al., 2015). In all subregions, REF increases with wind speed (Fig. 4d), likely due to dynamic droplet growth in a more turbulent boundary layer.

The partial dependence of $\mathrm{CF}$ on the zonal wind field at $600 \mathrm{hPa}$ shows a decrease in the southern subregions, when strong westerly winds are prevailing, and may indicate cloud- free areas in more convectively driven systems (Fig. 4e). Weak tendencies of a CF enhancement in the southern subregions and a $\mathrm{CF}$ decrease in the NW due to stronger easterly winds are apparent and may indicate the influence of the South African Easterly Jet, as discussed in Adebiyi and Zuidema (2016). As shown in Fig. 4f, REF is largely insensitive towards the zonal wind fields at $600 \mathrm{hPa}$, presenting a strong effect only in the SW, where westerly winds are associated with larger droplets. These characteristics may support the effect of westerly disturbances, which are more frequent in the SW.

Figure 5 shows the two-variable partial dependencies of REF on latitudinal and longitudinal air-mass origins for all four subregions, underlining regional differences in the susceptibility of REF to large-scale dynamical changes. In the $\mathrm{SW}$, air masses originating from the far $\mathrm{SW}$ are connected to larger REF than air masses from the NE (Fig. 5c). In contrast, in the NE, larger REFs are attributed to more humid air masses from the west (Fig. 5b), while easterly and probably drier winds from the continent favor smaller REF. The origin of air masses is more important for droplet size in the SW than in the NE through its higher subregional variability as a result of the occasional propagation of westerly disturbances. 


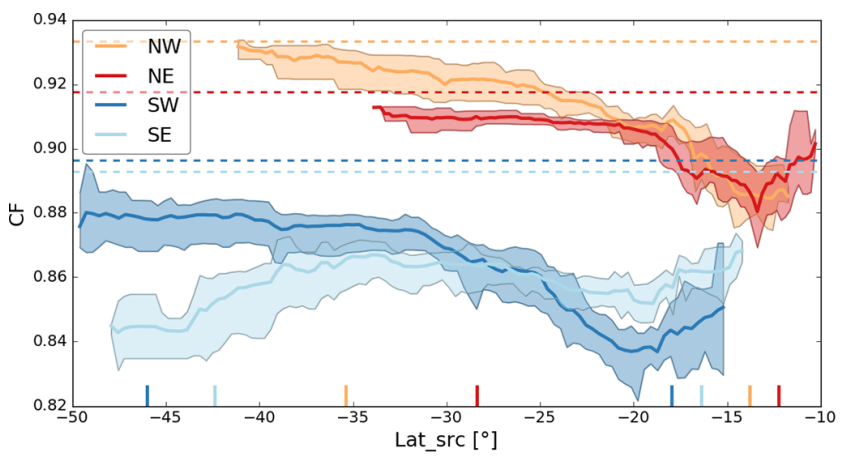

(a)

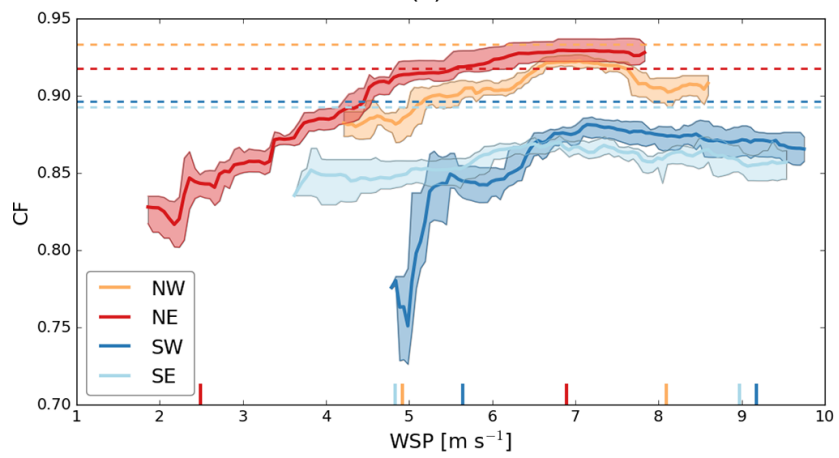

(c)

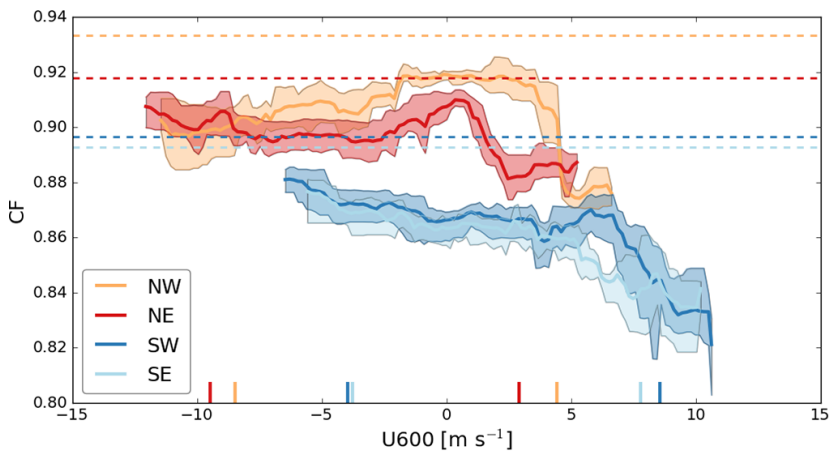

(e)

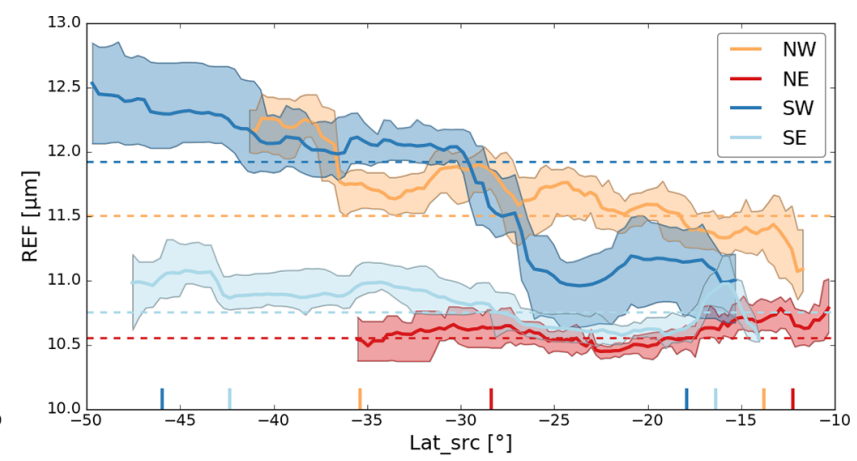

(b)

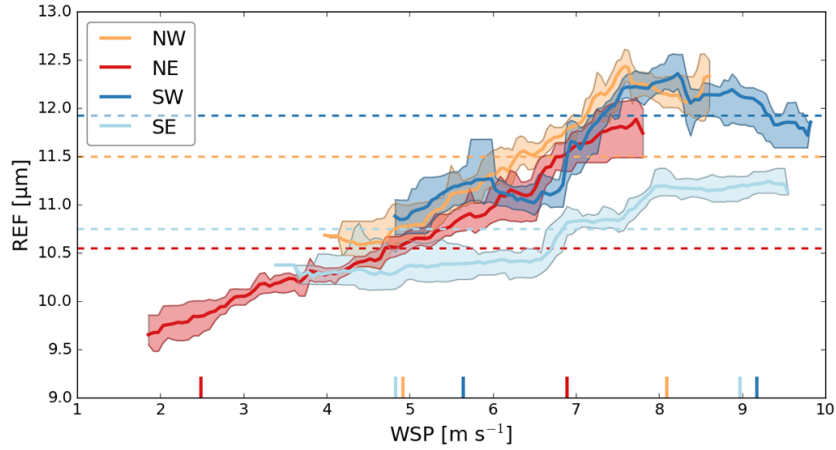

(d)

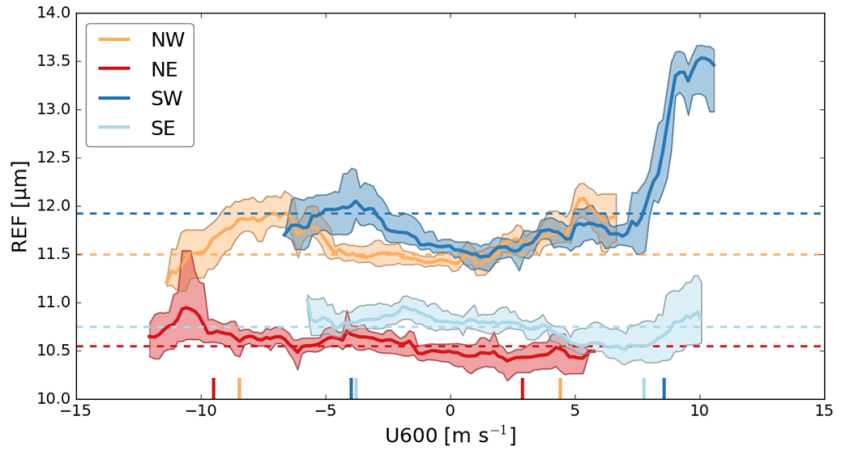

(f)

Figure 4. Mean partial dependence of CF and REF on source latitude of air mass (a, b), surface wind speed (c, d) and zonal winds at $600 \mathrm{hPa}$ $(\mathbf{e}, \mathbf{f})$ in the four subregions (colors) during JAS. Details as in Fig. 3.

\subsubsection{Conditions of aerosol-cloud interactions}

Although the impact of aerosols on cloud properties tends to be relatively weak on the temporal and spatial scales considered, characteristic patterns are obtained in the different subregions. CF increases with AOD in all subregions, especially in the southern subregions, as shown in Fig. 6a. This relation is found in many studies and can have both artificial and physical reasons (e.g., Mauger and Norris, 2007; Gryspeerdt et al., 2016; Andersen et al., 2017; Adebiyi and Zuidema, 2018). The observed relation may be physically induced through the availability of CCNs; increasing cloud lifetime and fractional cloudiness as aerosols are present (cf. Albrecht, 1989). It may be further explained by semidirect effects, where absorbing carbonaceous aerosol layers heat the free troposphere, causing a stabilization of the atmosphere that promotes the humidification of the cloud layer (cf. Li et al., 2013). Whether stability is enhanced by absorbing aerosols or is connected to the transport of aerosolloaded warm air cannot be answered at this point. The effect of AOD enhancement on the AOD-CF relation due to hygroscopic swelling (Quaas et al., 2010) and wind-induced sea spray (Engström and Ekman, 2010) is thought to play a minor role due to the explicit consideration of relative humidity and surface wind speed in the statistical models. In the $\mathrm{NE}$, the reason for the strong AOD-CF relation $(<5$ th percentile of AOD) is intriguing but it is unclear to what extent it is caused by aerosol-related physical processes. It should be noted that these conditions only rarely occur. 
(a) NW

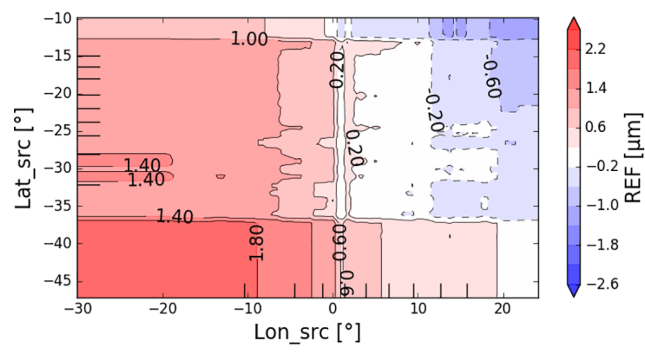

(c) SW

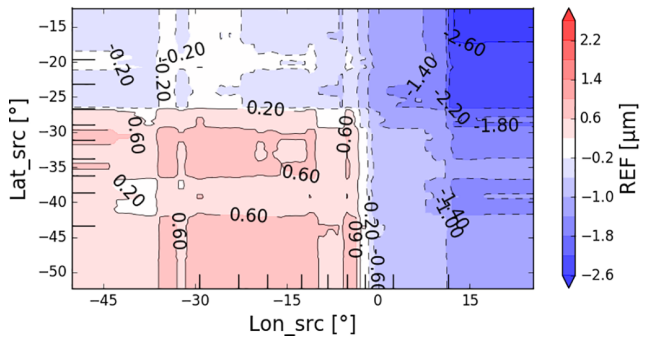

(b) NE

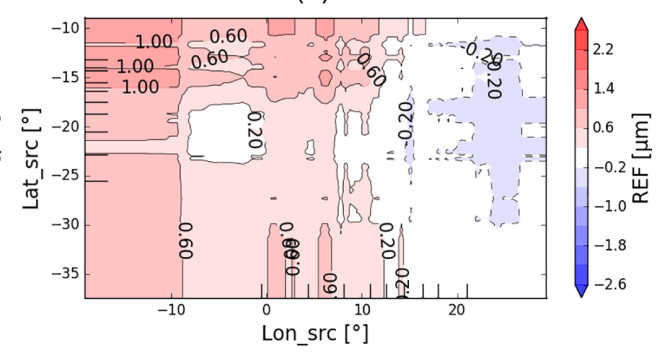

(d) SE

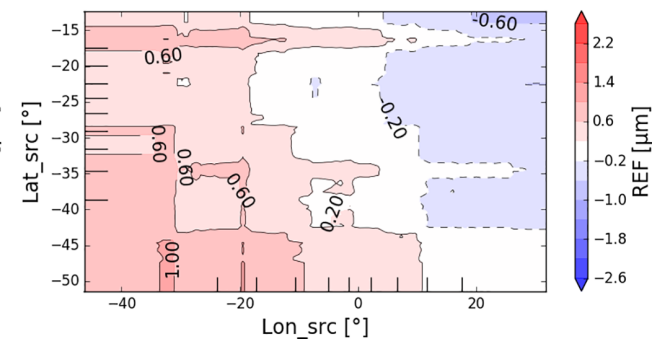

Figure 5. Two-variable partial dependence of REF on Lon_src and Lat_src in the in the four subregions (a) NW, (b) NE, (c) SW and (d) SE during JAS. Solid (dashed) contour lines indicate positive (negative) deviation of the predicted mean. The tick marks on the $x$ axis and $y$ axis indicate the deciles of the observations. For this illustration only one model run is selected at random as it represents all model runs with error ranges comparable to that of the one-variable partial dependencies.

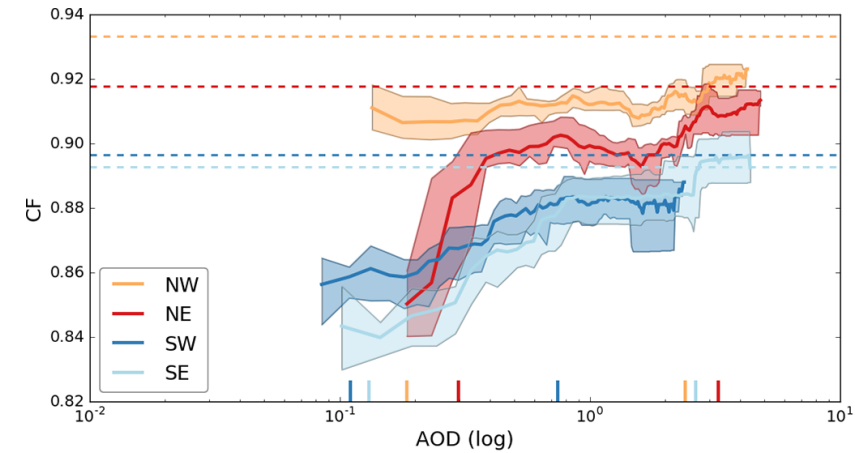

(a)

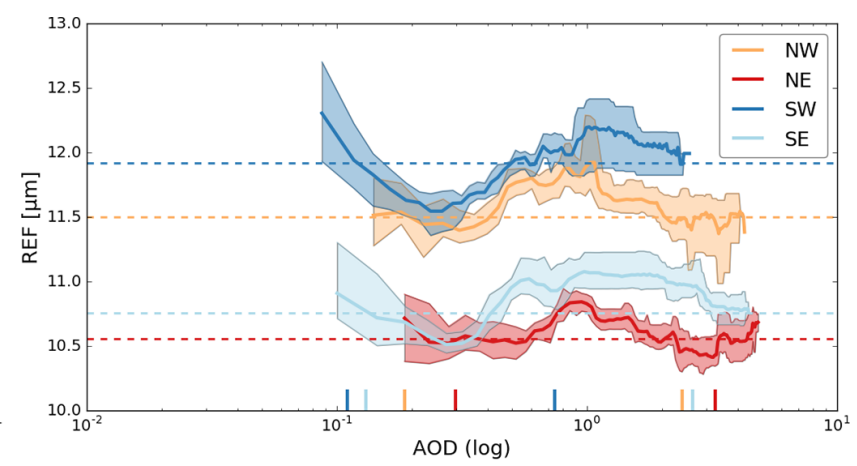

(b)

Figure 6. Mean partial dependence of CF (a) and REF (b) on AOD in the four subregions (colors) during JAS. Description as in Fig. 3.

The partial dependence of REF on the aerosol loading is shown in Fig. 6b. The southern subregions show a comparable pattern of a REF decrease up to AOD values of $\sim 0.2$. A subsequent REF increase up to an AOD of $\sim 1$ can be noticed in all subregions. The response of REF at lower AOD values is especially marked in the SW. Here, a different aerosol regime (composition and size: i.e., sea salt in the SW vs. biomass burning in the NE), giant cloud condensation nuclei, larger droplets in more turbulent conditions and the closer vicinity of aerosol and cloud layers may favor stronger aerosol indirect effects (cf. Andreae and Rosenfeld, 2008; Costantino and Bréon, 2013; Painemal et al., 2014; Andersen and Cermak, 2015). Stronger aerosol effects at low aerosol loadings were also found by Andersen et al. (2016) at a global scale. These results point to a saturation of the aerosol indirect effect under highly polluted conditions, where the influence of stability may be stronger. To what extent the relationship between REF and the AOD can be attributed to an absorbing aerosol bias in the satellite retrievals (Haywood et al., 2004) or physical processes cannot be answered definitively. However, the observed subregional differences of the polluted NE versus the more pristine SW make aerosol indirect effects more likely than retrieval issues.

Figure 7 shows AOD-REF partial dependencies for the months of July and September separately. While REF seems to decrease with increasing AOD during July (especially in the SW subregion), during September the opposite relationship is found. The contrasting relationships may be related to differences in the vertical distribution of aerosols and clouds in the southeast Atlantic. During July, aerosol and cloud lay- 


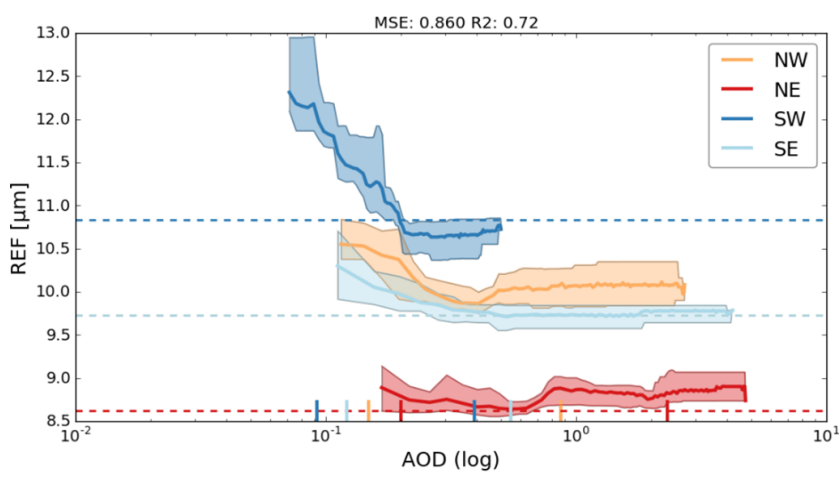

(a)

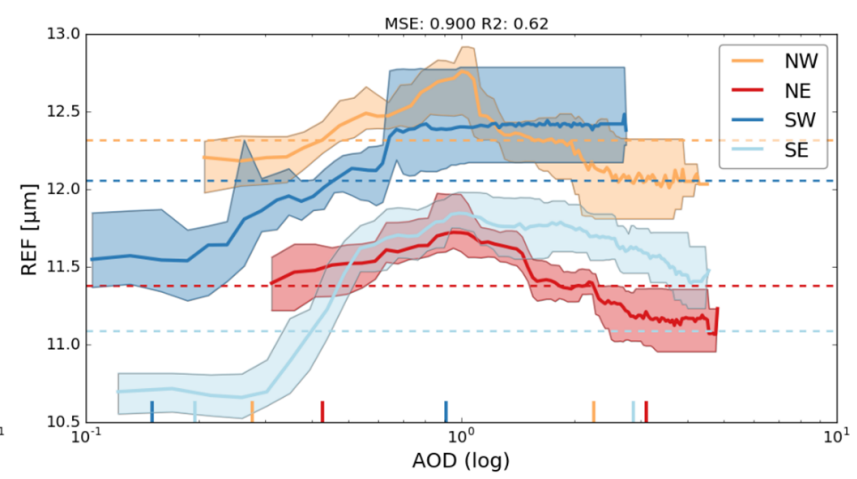

(b)

Figure 7. Mean partial dependence of REF on AOD in the four subregions (colors) in July (a) and September (b). MSE and $r^{2}$ refer to monthly GBRT models based on $\backsim 600$ data points. Description as in Fig. 3.

ers are frequently entangled, facilitating ACI, whereas in September they can be well separated (Adebiyi et al., 2018). During this time, absorbing aerosol may increase the stability and trap humidity in the boundary layer, potentially leading to the observed relationship. The JAS partial dependence between AOD and REF can thus be viewed as a summary of these patterns. However, it is not the study's focus to separate the different aerosol effects mentioned earlier, but to analyze the overall influence of aerosols on clouds during the biomass-burning season.

The two-variable partial dependencies, presented in Figs. 8 to 12 , show how the sensitivities of CF and REF to aerosol loading may vary under different meteorological conditions, i.e. LTS and relative humidity at 950 and $850 \mathrm{hPa}$. All subregions of the SEA are characterized by a stronger CF (Fig. 8) and REF sensitivity (Fig. 9) to LTS compared to AOD. In the southern subregions, $\mathrm{CF}$ is increased under stable and strongly polluted conditions. Here, the increase in CF with AOD is more pronounced in stable conditions, presumably due to reduced dry-air entrainment (cf. Chen et al., 2014), while CF seems to be less sensitive to aerosols in unstable conditions, where primarily low CF may result from cloud breakups in midlatitude cyclones (cf. Toniazzo et al., 2011). In contrast, a generally higher REF sensitivity to aerosols characterizes the SW. In this subregion, larger droplets may more effectively persist and grow and are thus susceptible to aerosols in both stable and unstable (mixing of aerosols into the cloud layer) conditions (cf. Painemal et al., 2014). In the NE, it can further be observed that the CF sensitivity to aerosols is favored at low aerosol loading, which might be explained by the saturation of aerosol effects at higher loading (cf. de Szoeke et al., 2016).

The relation of CF (REF), humidity at $950 \mathrm{hPa}$ and AOD is shown in Fig. 10 (11). Humidity at $950 \mathrm{hPa}$ dominates all subregions, particularly the SE, while the impact of aerosols is relatively small. In the southern subregions, though, CF increases under humid and polluted conditions (Fig. 10c, d). $\mathrm{CF}$ is especially sensitive to an increase in aerosol loading below a cloud-level humidity of $\sim 80 \%$, while above this level aerosol swelling is more likely to affect the AOD retrieval (cf. Adebiyi and Zuidema, 2018). As shown for CF, relative humidity is essentially related to REF, and a reduction in REF due to aerosols is apparent throughout the different humidity ranges at 850 and $950 \mathrm{hPa}$ (Figs. 11 and 12). In the SW (Fig. 12c), REF may be sensitive in drier as well as more humid conditions: while humid conditions provide larger droplets, entrainment induced by aerosols may more effectively reduce droplet size in dry conditions (cf. Chen et al., 2014).

In sum, the presented results show the potential of observing ACI susceptibilities in different thermodynamic conditions. Nevertheless, the presented link between meteorological conditions and aerosol effect on clouds (indirect and semidirect) is not necessarily causal and further effects due to aerosol processing near clouds and satellite artifacts (Sect. 2.3) may contribute to the observed cloud sensitivities.

\section{Conclusions}

In this study relevant mechanisms for changes in $\mathrm{CF}$ and REF are analyzed by using a GBRT model in four subregions of the southeast Atlantic. The GBRT models perform significantly better than multiple regression analyses based on the same data (average $r^{2}$ of 0.72 vs. 0.48 , respectively). This indicates that the GBRT models can be used to adequately represent the interactions governing the cloud system, while the methodical approach proves advantageous. The model skill varies with subregion and cloud property and features different sensitivities to the same predictor set. Outcomes of the GBRTs provide useful insights of important determinants for cloud properties. By accounting for meteorological conditions and aerosol loadings the models can help untangle the various cloud processes and cloud sensitivities to aerosols in the subregions of the SEA. The subregional importance and patterns of cloud drivers and ACI sensitivities is plausi- 
(a) NW

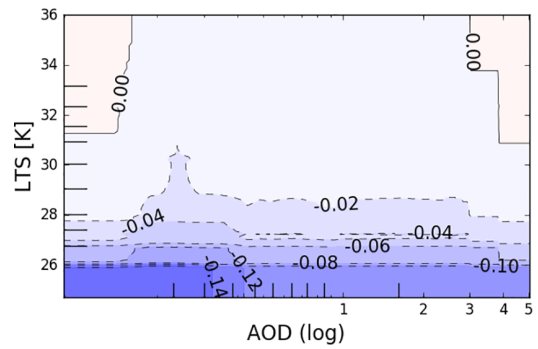

(c) SW

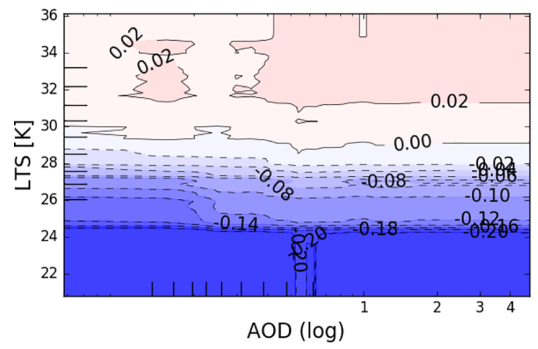

(b) NE

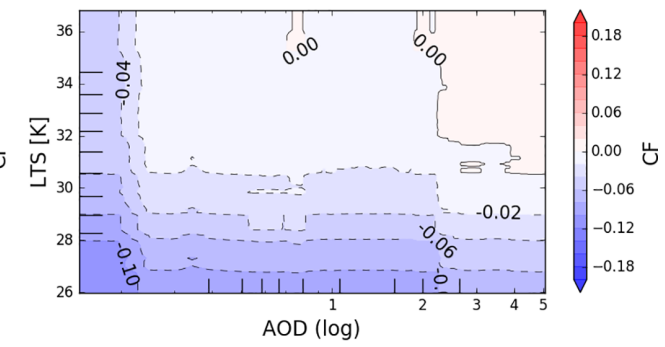

(d) SE

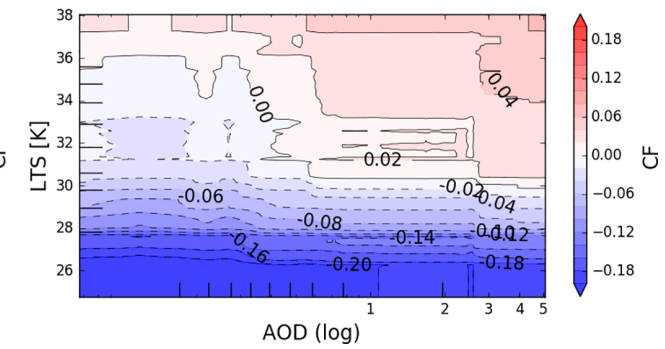

Figure 8. Two-variable partial dependence of CF on LTS and AOD in the four subregions NW (a), NE (b), SW (c) and SE (d) during JAS. Description as in Fig. 5.

(a) NW

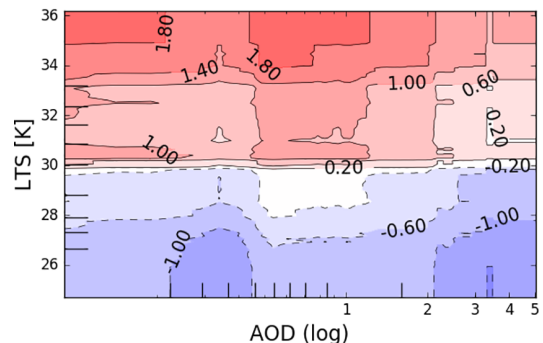

(c) SW

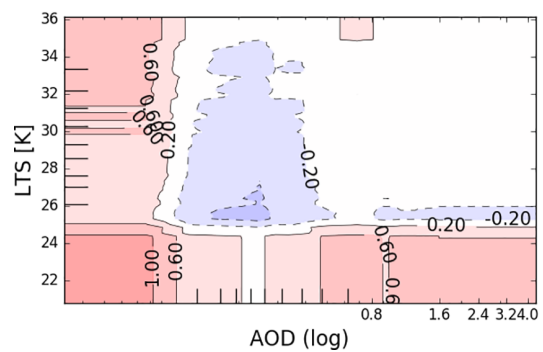

(b) NE
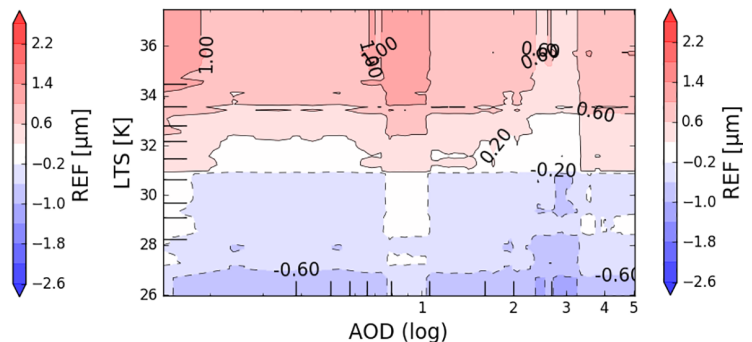

(d) SE
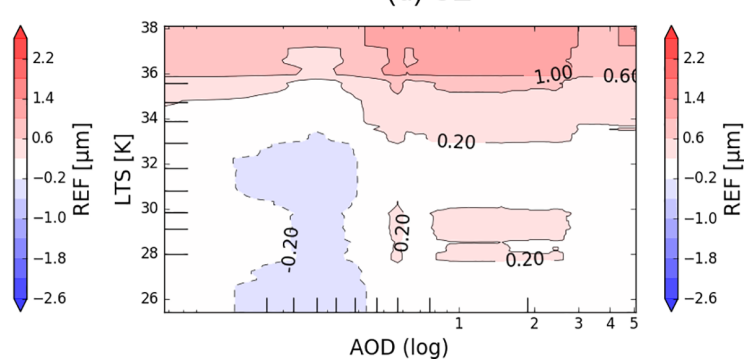

Figure 9. Two-variable partial dependence of REF on LTS and AOD in the four subregions NW (a), NE (b), SW (c) and SE (d) during JAS. Description as in Fig. 5.

ble and in accordance with findings of related studies (e.g., Chen et al., 2014; McCoy et al., 2017; Adebiyi and Zuidema, 2018).

In the statistical models atmospheric stability, air-mass dynamics and relative humidity at cloud level are the most important drivers for changes in $\mathrm{CF}$ and REF, relative to the given set of predictors. The SEA cloud cover is dominated by LTS in all subregions. In the NE, cloud amount and droplet size is additionally controlled by surface wind speeds, while in the SE, both are essentially influenced by the availability of moisture. Large-scale dynamics is the main driver of changes of cloud properties in the SW.

The positive relation between LTS and CF obtained from the GBRT models is explained by the stabilization of the boundary layer dynamics, which promotes cloud amount and longevity. The sensitivity of CF to LTS is nonlinear and satu- 
(a) NW

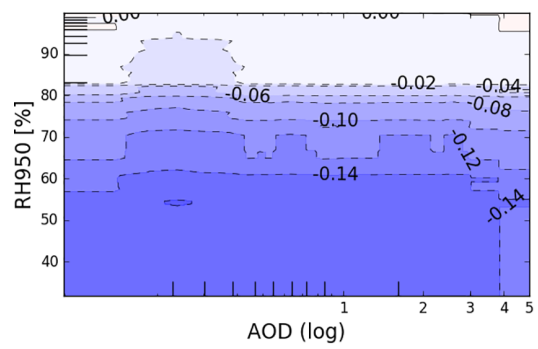

(c) SW

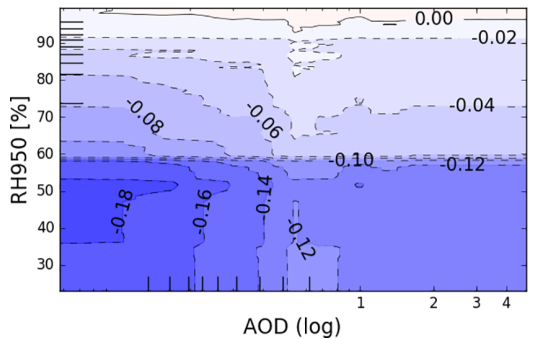

(b) NE

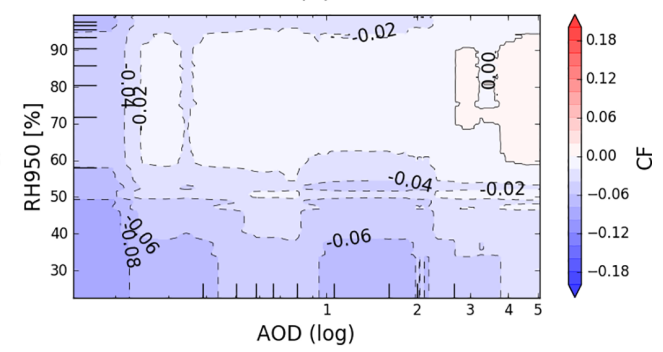

(d) SE

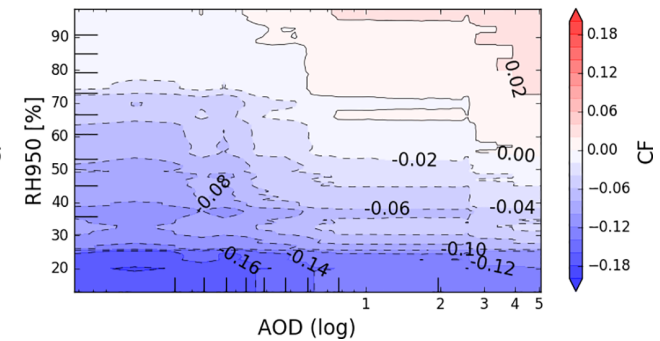

Figure 10. Two-variable partial dependence of CF on RH950 and AOD in the four subregions NW (a), NE (b), SW (c) and SE (d) during JAS. Description as in Fig. 5.

(a) NW

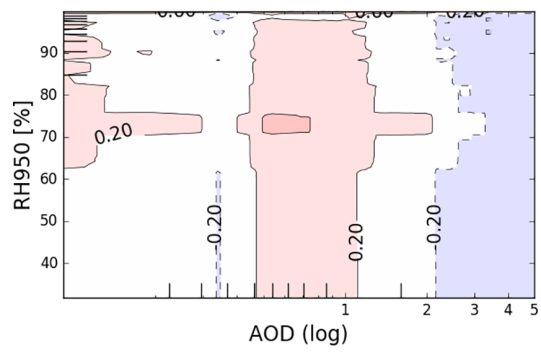

(c) SW

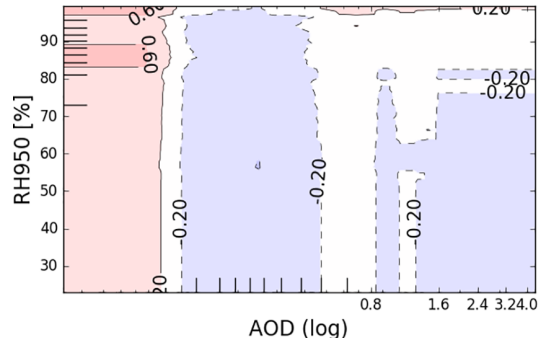

(b) NE
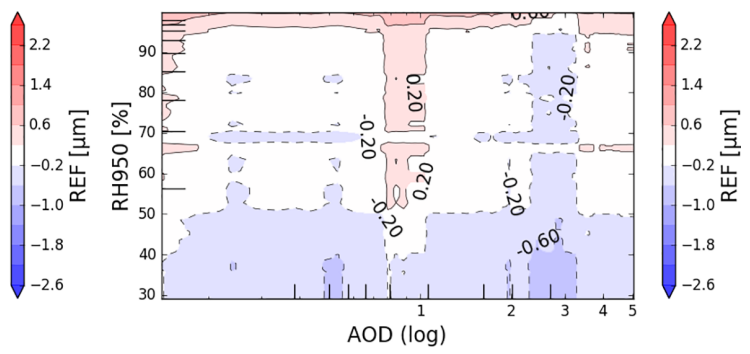

(d) SE
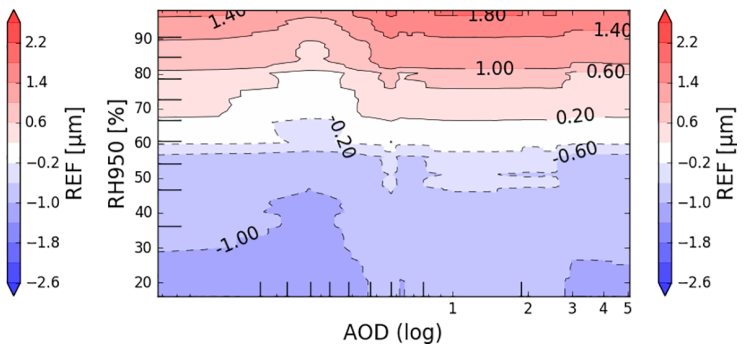

Figure 11. Two-variable partial dependence of REF on RH950 and AOD in the four subregions NW (a), NE (b), SW (c) and SE (d) during JAS. Description as in Fig. 5.

rates in stable conditions of LTS $>\sim 30 \mathrm{~K}$. LTS is especially important in the southern subregions, which are exposed to more variable atmospheric states.

Air-mass dynamics (air-mass origin and zonal wind speeds at $600 \mathrm{hPa}$ ) determine REF in the SW to a greater extent than in the NE. The REF increase in the SW is attributed to the outreach of convective westerly disturbances to this subregion. In the NE, air masses show less variability as they approach mainly from the continent under more stable condi- tions. Here, dynamically induced strong wind speeds and a warm free troposphere are associated with larger droplets.

Although aerosols play a secondary role for the prediction of cloud properties, important implications for the subregional strength of ACI can be derived from the model's partial dependencies. In the southern subregions, a strong sensitivity of CF and REF to AOD is modeled, likely due to aerosol-cloud interactions and semidirect effects. CF sensitivities to aerosols are shown to be stronger in stable condi- 
(a) NW

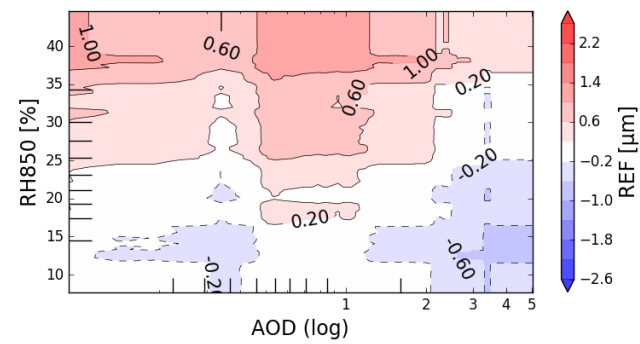

(c) SW

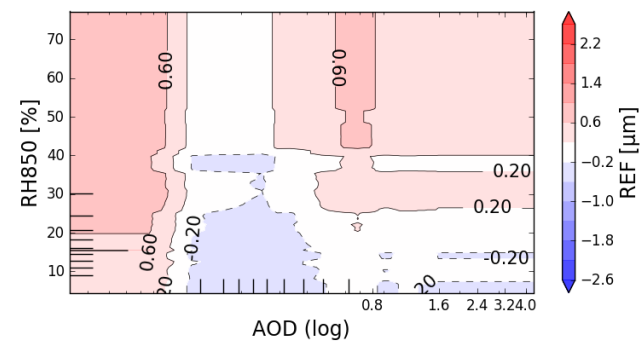

(b) NE

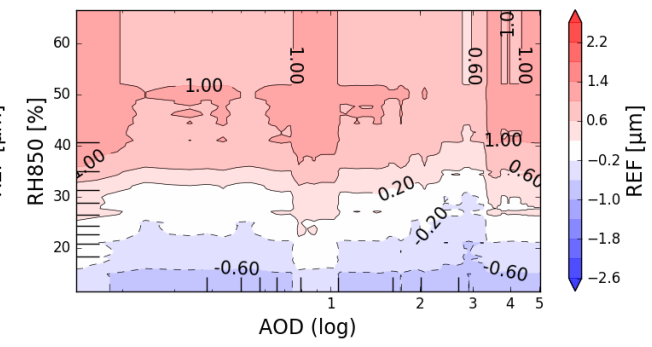

(d) SE

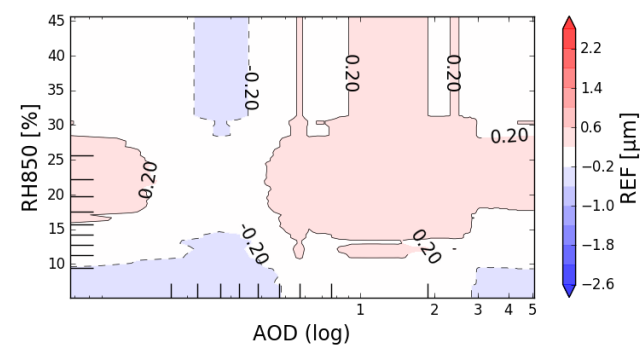

Figure 12. Two-variable partial dependence of REF on RH850 and AOD in the four subregions NW, NE, SW and SE during JAS. Description as in Fig. 5.

tions, where dry-air entrainment is reduced. A higher REF sensitivity in unstable conditions is attributed to, for example, generally larger droplets, a different aerosol composition (e.g., sea salt) and a more turbulent layer, which possibly favors stronger aerosol indirect effects in these regions. Outcomes also point to the saturation of the aerosol indirect effect in the NE compared to the SW where low aerosol loadings may more efficiently act as cloud condensation nuclei.

This study presents the potential of using multivariate GBRTs to derive cloud determinants and nonlinear sensitivities and further to give realistic estimates of the magnitude of aerosol relationships on a synoptic scale. Due to the limited capability of a statistical model to learn the data inherent relations only, feedback mechanisms and satellite artifacts in the SEA cannot completely be accounted for. However, the application of machine learning techniques is advantageous and yields valuable insights into subregional cloud and ACI processes on the microphysical and macrophysical scale.

Data availability. The Aqua/MODIS Atmosphere 8-Day L3 Global 1 Deg. dataset (08_E3) used in this study was acquired from the Level-1 and Atmosphere Archive and Distribution System (LAADS) Distributed Active Archive Center (DAAC), located in the Goddard Space Flight Center in Greenbelt, Maryland (https://ladsweb.nascom.nasa.gov/, last access: 19 November 2018). The ERA-Interim reanalysis data set of the European Centre for Medium-Range Weather Forecasts (ECMWF) was obtained from the ECMWF archive catalogue (http://apps.ecmwf.int/ datasets/data/interim-full-daily/levtype=pl/, last access: 19 November 2018). CALIPSO data were accessed through the NASA Lan- gley Research Center Atmospheric Science Data Center (https: //eosweb.larc.nasa.gov, last access: 19 November 2018).

Author contributions. JF and JC had the initial research idea. JF fully developed the concept and methodology. JF wrote the software and implemented supporting algorithms. JF conducted the data curation, data analysis and wrote the original manuscript. JC and HA reviewed and edited the original draft and contributed to the interpretation of the results.

Competing interests. The authors declare that they have no conflict of interest.

Special issue statement. This article is part of the special issue "New observations and related modelling studies of the aerosolcloud-climate system in the Southeast Atlantic and southern Africa regions (ACP/AMT inter-journal SI)". It is not associated with a conference.

Acknowledgements. MODIS data were obtained from the Goddard Space Flight Center (https://ladsweb.modaps.eosdis. nasa.gov/search/, last access: 16 November 2018). The authors gratefully acknowledge the NOAA Air Resources Laboratory (ARL) for the provision of the HYSPLIT transport model (http://ready.arl.noaa.gov/HYSPLIT.php, last access: 19 November 2018). ERA-Interim data were obtained from the homepage of European Centre for Medium-Range Weather Forecasts (http://apps.ecmwf.int/datasets/data/interim-full-daily/levtype=pl/, last access: 19 November 2018). CALIPSO data were accessed 
through the NASA Langley Research Center Atmospheric Science Data Center (https://eosweb.larc.nasa.gov, last access: 19 November 2018). The contribution of Hendrik Andersen was supported by Deutsche Forschungsgemeinschaft (DFG) in the project Namib Fog Life Cycle Analysis (NaFoLiCA), CE 163/7-1. The valuable comments of two anonymous reviewers and the editor helped improve the original paper.

The article processing charges for this open-access publication were covered by a Research

Centre of the Helmholtz Association.

Edited by: Timothy J. Dunkerton

Reviewed by: two anonymous referees

\section{References}

Adebiyi, A. A. and Zuidema, P.: The role of the southern African easterly jet in modifying the southeast Atlantic aerosol and cloud environments, Q. J. Roy. Meteor. Soc., 142, 1574-1589, https://doi.org/10.1002/qj.2765, 2016.

Adebiyi, A. A. and Zuidema, P.: Low Cloud Cover Sensitivity to Biomass-Burning Aerosols and Meteorology over the Southeast Atlantic, J. Climate, 31, 4329-4346, https://doi.org/10.1175/JCLI-D-17-0406.1, 2018.

Adebiyi, A. A., Zuidema, P., and Abel, S. J.: The Convolution of Dynamics and Moisture with the Presence of Shortwave Absorbing Aerosols over the Southeast Atlantic, J. Climate, 28, 19972024, https://doi.org/10.1175/JCLI-D-14-00352.1, 2015.

Albrecht, B. A.: Aerosols, Cloud Microphysics, and Fractional Cloudiness, Science, 245, 1227-1230, https://doi.org/10.1126/science.245.4923.1227, 1989.

Andersen, H. and Cermak, J.: How thermodynamic environments control stratocumulus microphysics and interactions with aerosols, Environ. Res. Lett., 10, 024004, https://doi.org/10.1088/1748-9326/10/2/024004, 2015.

Andersen, H., Cermak, J., Fuchs, J., and Schwarz, K.: Global observations of cloud-sensitive aerosol loadings in low-level marine clouds, J. Geophys. Res.-Atmos., 121, 12936-12946, https://doi.org/10.1002/2016JD025614, 2016.

Andersen, H., Cermak, J., Fuchs, J., Knutti, R., and Lohmann, U.: Understanding the drivers of marine liquid-water cloud occurrence and properties with global observations using neural networks, Atmos. Chem. Phys., 17, 9535-9546, https://doi.org/10.5194/acp-17-9535-2017, 2017.

Andreae, M. and Rosenfeld, D.: Aerosol-cloud-precipitation interactions. Part 1. The nature and sources of cloud-active aerosols, Earth-Sci. Rev., 89, 13-41, https://doi.org/10.1016/j.earscirev.2008.03.001, 2008.

Bond, T. C., Doherty, S. J., Fahey, D. W., Forster, P. M., Berntsen, T., DeAngelo, B. J., Flanner, M. G., Ghan, S., Kärcher, B., Koch, D., Kinne, S., Kondo, Y., Quinn, P. K., Sarofim, M. C., Schultz, M. G., Schulz, M., Venkataraman, C., Zhang, H., Zhang, S., Bellouin, N., Guttikunda, S. K., Hopke, P. K., Jacobson, M. Z., Kaiser, J. W., Klimont, Z., Lohmann, U., Schwarz, J. P., Shindell, D., Storelvmo, T., Warren, S. G., and Zender, C. S.: Bounding the role of black carbon in the climate system: A sci- entific assessment, J. Geophys. Res.-Atmos., 118, 5380-5552, https://doi.org/10.1002/jgrd.50171, 2013.

Bony, S. and Dufresne, J.-L.: Marine boundary layer clouds at the heart of tropical cloud feedback uncertainties in climate models, Geophys. Res. Lett., 32, L20806, https://doi.org/10.1029/2005GL023851, 2005.

Boucher, O., Randall, D., Artaxo, P., Bretherton, C., Feingold, G., Forster, P., Kerminen, V.-M., Kondo, Y., Liao, H., Lohmann, U., Rasch, P., Satheesh, S. K., Sherwood, S., Stevens, B., Zhang, X. Y., and Zhan, X. Y.: Clouds and Aerosols, in: Climate Change 2013 - The Physical Science Basis, edited by: Intergovernmental Panel on Climate Change, 7, 571-658, Cambridge University Press, Cambridge, https://doi.org/10.1017/CBO9781107415324.016, 2013.

Bretherton, C. S. and Wyant, M. C.: Moisture Transport, Lower-Tropospheric Stability, and Decoupling of Cloud-Topped Boundary Layers, J. Atmos. Sci., 54, 148-167, https://doi.org/10.1175/15200469(1997)054<0148:MTLTSA>2.0.CO;2, 1997.

Bretherton, C. S., Blossey, P. N., and Jones, C. R.: Mechanisms of marine low cloud sensitivity to idealized climate perturbations: A single-LES exploration extending the CGILS cases, J. Adv. Model. Earth Sy., 5, 316-337, https://doi.org/10.1002/jame.20019, 2013.

Brueck, M., Nuijens, L., and Stevens, B.: On the Seasonal and Synoptic Time-Scale Variability of the North Atlantic Trade Wind Region and Its Low-Level Clouds, J. Atmos. Sci., 72, 14281446, https://doi.org/10.1175/JAS-D-14-0054.1, 2015.

Carslaw, D. C. and Taylor, P. J.: Analysis of air pollution data at a mixed source location using boosted regression trees, Atmos. Environ., 43, 3563-3570, https://doi.org/10.1016/j.atmosenv.2009.04.001, 2009.

Chand, D., Wood, R., Anderson, T. L., Satheesh, S. K., and Charlson, R. J.: Satellite-derived direct radiative effect of aerosols dependent on cloud cover, Nat. Geosci., 2, 181-184, https://doi.org/10.1038/ngeo437, 2009.

Chen, Y.-C., Christensen, M. W., Stephens, G. L., and Seinfeld, J. H.: Satellite-based estimate of global aerosol-cloud radiative forcing by marine warm clouds, Nat. Geosci., 7, 643-646, https://doi.org/10.1038/ngeo2214, 2014.

Christensen, M. W., Neubauer, D., Poulsen, C. A., Thomas, G. E., McGarragh, G. R., Povey, A. C., Proud, S. R., and Grainger, R. G.: Unveiling aerosol-cloud interactions - Part 1: Cloud contamination in satellite products enhances the aerosol indirect forcing estimate, Atmos. Chem. Phys., 17, 13151-13164, https://doi.org/10.5194/acp-17-13151-2017, 2017.

Costantino, L. and Bréon, F.-M.: Aerosol indirect effect on warm clouds over South-East Atlantic, from co-located MODIS and CALIPSO observations, Atmos. Chem. Phys., 13, 69-88, https://doi.org/10.5194/acp-13-69-2013, 2013.

de Szoeke, S. P., Verlinden, K. L., Yuter, S. E., and Mechem, D. B.: The time scales of variability of marine low clouds, J. Climate, 29, 6463-6481, https://doi.org/10.1175/JCLI-D-150460.1, 2016.

Dee, D. P., Uppala, S. M., Simmons, A. J., Berrisford, P., Poli, P., Kobayashi, S., Andrae, U., Balmaseda, M. A., Balsamo, G., Bauer, P., Bechtold, P., Beljaars, A. C. M., van de Berg, L., Bidlot, J., Bormann, N., Delsol, C., Dragani, R., Fuentes, M., Geer, A. J., Haimberger, L., Healy, S. B., Hersbach, H., Hólm, E. V., 
Isaksen, L., Kållberg, P., Köhler, M., Matricardi, M., McNally, A. P., Monge-Sanz, B. M., Morcrette, J.-J., Park, B.-K., Peubey, C., de Rosnay, P., Tavolato, C., Thépaut, J.-N., and Vitart, F.: The ERA-Interim reanalysis: configuration and performance of the data assimilation system. Q. J. Roy. Meteorol. Soc., 137, 553597, https://doi.org/10.1002/qj.828, 2011.

Eastman, R., Wood, R., and Bretherton, C. S.: Time Scales of Clouds and Cloud-Controlling Variables in Subtropical Stratocumulus from a Lagrangian Perspective, J. Atmos. Sci., 73, 30793091, https://doi.org/10.1175/JAS-D-16-0050.1, 2016.

Engström, A. and Ekman, A. M. L.: Impact of meteorological factors on the correlation between aerosol optical depth and cloud fraction, Geophys. Res. Lett., 37, L18814, https://doi.org/10.1029/2010GL044361, 2010.

Fan, J., Wang, Y., Rosenfeld, D., Liu, X., Fan, J., Wang, Y., Rosenfeld, D., and Liu, X.: Review of Aerosol-Cloud Interactions: Mechanisms, Significance, and Challenges, J. Atmos. Sci., 73, 4221-4252, https://doi.org/10.1175/JAS-D-16-0037.1, 2016.

Friedman, J. H.: Greedy function approximation: A gradient boosting machine, Ann. Stat., 29, 1189-1232, https://doi.org/10.1214/aos/1013203451, 2001.

Fuchs, J., Cermak, J., Andersen, H., Hollmann, R., and Schwarz, K.: On the Influence of Air Mass Origin on Low-Cloud Properties in the Southeast Atlantic, J. Geophys. Res.-Atmos., 122, 1107611091, https://doi.org/10.1002/2017JD027184, 2017.

Grandey, B. S., Stier, P., and Wagner, T. M.: Investigating relationships between aerosol optical depth and cloud fraction using satellite, aerosol reanalysis and general circulation model data, Atmos. Chem. Phys., 13, 3177-3184, https://doi.org/10.5194/acp-13-3177-2013, 2013.

Gryspeerdt, E., Quaas, J., and Bellouin, N.: Constraining the aerosol influence on cloud fraction, J. Geophys. Res.-Atmos., 121, 35663583, https://doi.org/10.1002/2015JD023744, 2016.

Hastie, T., Tibshirani, R., and Friedman, J.: The Elements of Statistical Learning, Springer Series in Statistics, Springer New York, New York, 2 edn., https://doi.org/10.1007/978-0-387-84858-7, 2009.

Haywood, J. M., Osborne, S. R., and Abel, S. J.: The effect of overlying absorbing aerosol layers on remote sensing retrievals of cloud effective radius and cloud optical depth, Q. J. Roy. Meteor. Soc., 130, 779-800, https://doi.org/10.1256/qj.03.100, 2004.

Hubanks, P., King, M., Platnick, S., and Pincus, R.: MODIS Atmosphere L3 Gridded Product Algorithm Theoretical Basis Document No. ATBD-MOD-30 for Level-3 Global Gridded Atmosphere Products (08_D3, 08_E3, 08_M3) and Users Guide, available at: https://modis-atmos.gsfc.nasa.gov/sites/ default/files/ModAtmo/L3_ATBD_C6_2018_04_11.pdf (last access: 19 November 2018), 2018.

Huber, P. J.: Robust Estimation of a Location Parameter, Ann. Math. Stat., 35, 73-101, https://doi.org/10.1214/aoms/1177703732, 1964.

Johnson, B. T., Shine, K. P., and Forster, P. M.: The semidirect aerosol effect: Impact of absorbing aerosols on marine stratocumulus, Q. J. Roy. Meteor. Soc., 130, 1407-1422, https://doi.org/10.1256/qj.03.61, 2004.

Jones, C. R., Bretherton, C. S., and Blossey, P. N.: Fast stratocumulus time scale in mixed layer model and large eddy simulation, J. Adv. Model. Earth Sy., 6, 206-222, https://doi.org/10.1002/2013MS000289, 2014.
Kaufman, Y., Remer, L., Tanre, D., Rong-Rong Li, Kleidman, R., Mattoo, S., Levy, R., Eck, T., Holben, B., Ichoku, C., Martins, J., and Koren, I.: A critical examination of the residual cloud contamination and diurnal sampling effects on MODIS estimates of aerosol over ocean, IEEE T. Geosci. Remote, 43, 2886-2897, https://doi.org/10.1109/TGRS.2005.858430, 2005.

Kaufman, Y. J.: Dust transport and deposition observed from the Terra-Moderate Resolution Imaging Spectroradiometer (MODIS) spacecraft over the Atlantic Ocean, J. Geophys. Res., 110, D10S12, https://doi.org/10.1029/2003JD004436, 2005.

Kaufman, Y. J.: Smoke and Pollution Aerosol Effect on Cloud Cover, Science, 313, 655-658, https://doi.org/10.1126/science.1126232, 2006.

Kazil, J., Feingold, G., and Yamaguchi, T.: Wind speed response of marine non-precipitating stratocumulus clouds over a diurnal cycle in cloud-system resolving simulations, Atmos. Chem. Phys., 16, 5811-5839, https://doi.org/10.5194/acp-165811-2016, 2016.

Klein, S. and Hartmann, D.: The seasonal cycle of low stratiform clouds, J. Climate, 6, 1587-1606, 1993.

Klein, S. A.: Synoptic Variability of Low-Cloud Properties and Meteorological Parameters in the Subtropical Trade Wind Boundary Layer, J. Climate, 10, 2018-2039, https://doi.org/10.1175/15200442(1997)010<2018:SVOLCP>2.0.CO;2, 1997.

Klein, S. A., Hartmann, D. L., and Norris, J. R.: On the Relationships among Low-Cloud Structure, Sea Surface Temperature, and Atmospheric Circulation in the Summertime Northeast Pacific, J. Climate, 8, 1140-1155, https://doi.org/10.1175/15200442(1995)008<1140:OTRALC >2.0.CO;2, 1995.

Lacagnina, C. and Selten, F.: A novel diagnostic technique to investigate cloud-controlling factors, J. Geophys. Res.-Atmos., 118, 5979-5991, https://doi.org/10.1002/jgrd.50511, 2013.

Levy, R. C., Mattoo, S., Munchak, L. A., Remer, L. A., Sayer, A. M., Patadia, F., and Hsu, N. C.: The Collection 6 MODIS aerosol products over land and ocean, Atmos. Meas. Tech., 6, 29893034, https://doi.org/10.5194/amt-6-2989-2013, 2013.

Li, J., Von Salzen, K., Peng, Y., Zhang, H., and Liang, X. Z.: Evaluation of black carbon semi-direct radiative effect in a climate model, J. Geophys. Res.-Atmos., 118, 4715-4728, https://doi.org/10.1002/jgrd.50327, 2013.

Mauger, G. S. and Norris, J. R.: Meteorological bias in satellite estimates of aerosol-cloud relationships, Geophys. Res. Lett., 34, L16824, https://doi.org/10.1029/2007GL029952, 2007.

Mauger, G. S. and Norris, J. R.: Assessing the Impact of Meteorological History on Subtropical Cloud Fraction, J. Climate, 23, 2926-2940, https://doi.org/10.1175/2010JCLI3272.1, 2010.

McCoy, D. T., Eastman, R., Hartmann, D. L., and Wood, R.: The change in low cloud cover in a warmed climate inferred from AIRS, MODIS, and ERA-interim, J. Climate, 30, 3609-3620, https://doi.org/10.1175/JCLI-D-15-0734.1, 2017.

Medeiros, B., Stevens, B., Held, I. M., Zhao, M., Williamson, D. L., Olson, J. G., and Bretherton, C. S.: Aquaplanets, Climate Sensitivity, and Low Clouds, J. Climate, 21, 4974-4991, https://doi.org/10.1175/2008JCLI1995.1, 2008.

Muhlbauer, A., McCoy, I. L., and Wood, R.: Climatology of stratocumulus cloud morphologies: microphysical properties and radiative effects, Atmos. Chem. Phys., 14, 6695-6716, https://doi.org/10.5194/acp-14-6695-2014, 2014. 
Myers, T. A. and Norris, J. R.: Observational evidence that enhanced subsidence reduces subtropical marine boundary layer cloudiness, J. Climate, 26, 7507-7524, https://doi.org/10.1175/JCLI-D-12-00736.1, 2013.

Natekin, A. and Knoll, A.: Gradient boosting machines, a tutorial, Front. Neurorobotics, 7, 21, https://doi.org/10.3389/fnbot.2013.00021, 2013.

Norris, J. R. and Iacobellis, S. F.: North Pacific cloud feedbacks inferred from synoptic-scale dynamic and thermodynamic relationships, J. Climate, 18, 4862-4878, https://doi.org/10.1175/JCLI3558.1, 2005.

Painemal, D. and Zuidema, P.: Microphysical variability in southeast Pacific Stratocumulus clouds: synoptic conditions and radiative response, Atmos. Chem. Phys., 10, 6255-6269, https://doi.org/10.5194/acp-10-6255-2010, 2010.

Painemal, D., Kato, S., and Minnis, P.: Boundary layer regulation in the southeast Atlantic cloud microphysics during the biomass burning season as seen by the A-train satellite constellation, J. Geophys. Res.-Atmos., 119, 11288-11302, https://doi.org/10.1002/2014JD022182, 2014.

Pedregosa, F., Varoquaux, G., Gramfort, A., Michel, V., Thirion, B., Grisel, O., Blondel, M., Louppe, G., Prettenhofer, P., Weiss, R., Dubourg, V., Vanderplas, J., Passos, A., Cournapeau, D., Brucher, M., Perrot, M., and Duchesnay, É.: Scikit-learn: Machine Learning in Python, J. Mach. Learn. Res., 12, 2825-2830, https://doi.org/10.1007/s13398-014-0173-7.2, 2011.

Platnick, S. and Twomey, S.: Determining the Susceptibility of Cloud Albedo to Changes in Droplet Concentration with the Advanced Very High Resolution Radiometer, J. Appl. Meteorol., 33, 334-347, https://doi.org/10.1175/15200450(1994)033<0334:DTSOCA>2.0.CO;2, 1994.

Quaas, J., Boucher, O., Bellouin, N., and Kinne, S.: Satellitebased estimate of the direct and indirect aerosol climate forcing, J. Geophys. Res.-Atmos., 113, D05204, https://doi.org/10.1029/2007JD008962, 2008.

Quaas, J., Stevens, B., Stier, P., and Lohmann, U.: Interpreting the cloud cover - aerosol optical depth relationship found in satellite data using a general circulation model, Atmos. Chem. Phys., 10, 6129-6135, https://doi.org/10.5194/acp-10-6129-2010, 2010.

Rahn, D. A. and Garreaud, R.: Marine boundary layer over the subtropical southeast Pacific during VOCALS-REx - Part 2: Synoptic variability, Atmos. Chem. Phys., 10, 4507-4519, https://doi.org/10.5194/acp-10-4507-2010, 2010.

Sayegh, A., Tate, J. E., and Ropkins, K.: Understanding how roadside concentrations of NOx are influenced by the background levels, traffic density, and meteorological conditions using Boosted Regression Trees, Atmos. Environ., 127, 163-175, https://doi.org/10.1016/j.atmosenv.2015.12.024, 2016.
Seinfeld, J. H., Bretherton, C., Carslaw, K. S., Coe, H., DeMott, P. J., Dunlea, E. J., Feingold, G., Ghan, S., Guenther, A. B., Kahn, R., Kraucunas, I., Kreidenweis, S. M., Molina, M. J., Nenes, A., Penner, J. E., Prather, K. A., Ramanathan, V., Ramaswamy, V., Rasch, P. J., Ravishankara, A. R., Rosenfeld, D., Stephens, G., and Wood, R.: Improving our fundamental understanding of the role of aerosol-cloud interactions in the climate system, P. Natl. Acad. Sci. USA, 113, 5781-5790, https://doi.org/10.1073/pnas.1514043113, 2016.

Stier, P.: Limitations of passive remote sensing to constrain global cloud condensation nuclei, Atmos. Chem. Phys., 16, 6595-6607, https://doi.org/10.5194/acp-16-6595-2016, 2016.

Toniazzo, T., Abel, S. J., Wood, R., Mechoso, C. R., Allen, G., and Shaffrey, L. C.: Large-scale and synoptic meteorology in the south-east Pacific during the observations campaign VOCALSREx in austral Spring 2008, Atmos. Chem. Phys., 11, 49775009, https://doi.org/10.5194/acp-11-4977-2011, 2011.

Twomey, S.: Pollution and the planetary albedo, Atmos. Environ., 8, 1251-1256, https://doi.org/10.1016/0004-6981(74)90004-3, 1974.

Várnai, T., Marshak, A., and Yang, W.: Multi-satellite aerosol observations in the vicinity of clouds, Atmos. Chem. Phys., 13, 38993908, https://doi.org/10.5194/acp-13-3899-2013, 2013.

Wilcox, E. M.: Stratocumulus cloud thickening beneath layers of absorbing smoke aerosol, Atmos. Chem. Phys., 10, 1176911777, https://doi.org/10.5194/acp-10-11769-2010, 2010.

Winker, D. M., Vaughan, M. A., Omar, A., Hu, Y., Powell, K. A., Liu, Z., Hunt, W. H., and Young, S. A.: Overview of the CALIPSO mission and CALIOP data processing algorithms, J. Atmos. Ocean. Tech., 26, 2310-2323, https://doi.org/10.1175/2009JTECHA1281.1, 2009.

Wood, R.: Stratocumulus Clouds, Mon. Weather Rev., 140, 23732423, https://doi.org/10.1175/MWR-D-11-00121.1, 2012.

Wood, R. and Bretherton, C. S.: On the Relationship between Stratiform Low Cloud Cover and Lower-Tropospheric Stability, J. Climate, 19, 6425-6432, https://doi.org/10.1175/JCLI3988.1, 2006.

Yamaguchi, T. and Randall, D. A.: Large-Eddy Simulation of Evaporatively Driven Entrainment in CloudTopped Mixed Layers, J. Atmos. Sci., 65, 1481-1504, https://doi.org/10.1175/2007JAS2438.1, 2008.

Zhang, Y., Stevens, B., Medeiros, B., and Ghil, M.: LowCloud Fraction, Lower-Tropospheric Stability, and Large-Scale Divergence, J. Climate, 22, 4827-4844, https://doi.org/10.1175/2009JCLI2891.1, 2009.

Zuidema, P., Redemann, J., Haywood, J., Wood, R., Piketh, S., Hipondoka, M., and Formenti, P.: Smoke and Clouds above the Southeast Atlantic: Upcoming Field Campaigns Probe Absorbing Aerosol's Impact on Climate, B. Am. Meteorol. Soc., 97, 1131-1135, https://doi.org/10.1175/BAMS-D-15-00082.1, 2016. 